\title{
Use of Statistical Process Control in Bus Fleet Maintenance at SEPTA
}

Anna Lynn Smith, Parsons Brinckerhoff Quade and Douglas, Inc.

Sohail S. Chaudhry, College of Commerce and Finance, Villanova University

\begin{abstract}
As a provider of public transportation services in the Philadelphia area, the Southeastern Pennsylvania Transportation Authority operates and maintains a large number of transit vehicles for daily use. In an attempt to improve service quality and reduce costs, the Southeastern Pennsylvania Transportation Authority underwent a program to train staff on the use of Statistical Process Control to track and address quality issues with its bus fleet. This research presents the steps taken by this public transit agency to implement Statistical Process Control on part of its bus fleet as one element of an overall quality improvement program.
\end{abstract}

\section{Introduction}

The public transit industry in the United States is heavily subsidized by Federal, State, and local funds that make up most of a transit agency's capital and operating funds. With an uncertain future for these subsidies, transit agencies are continually trying to find ways to reduce their costs. Fleet maintenance is one area in 
transit operations where opportunities for improving efficiency and experiencing cost savings are readily apparent.

This article describes the Southeastern Pennsylvania Transportation Authority's (SEPTA) use of Statistical Process Control (SPC) to track quality problems with its bus fleet. SEPTA used SPC as part of an overall quality improvement effort within the organization. SEPTA's deployment of SPC was relatively unique in the transit industry, and is of potential interest to other organizations in the public sector looking to improve the quality of their work performance.

The article begins with a brief literature review of quality efforts in the transit industry particularly those with SPC applications, and continues with a discussion of SEPTA's quality initiative and use of SPC. An example of SEPTA's in-process bus inspection procedure is detailed to illustrate the context of its SPC use. The article concludes with a discussion of the benefits SEPTA experienced from using SPC and the challenges faced with continued use.

\section{SPC in the Transit Industry}

The concept of Total Quality Management (TQM) became popular during the late 1980s and through the 1990s. Although its beginnings were in the private sector, some public organizations also embraced the concepts of TQM. In the transit industry, several agencies adopted TQM programs in an attempt to improve the efficiency or effectiveness of the establishment (Bowman and Hellein 1998; Obeng and Ugboro 1996; Schwager and MacDorman 1992; Takyi et al. 1993). To the best of our knowledge, there are no other articles on the application of SPC at public transit agencies in academic publications. However, in the transportation industry, some sort of performance measures including SPC is commonly used to track and monitor systems including on-time performance, vehicle breakdowns, and track condition (Anonymous 1998; Benneyan and Chute 1993; Pohlot 2003).

It was a jump in the private sector from manufacturing to shipping where SPC gained its footing in the transportation arena. Ford Motor Company successfully used SPC to facilitate the measurement and analysis of railroad transportation in its quest for quality improvement (Richards 1984). Ford found that the application of SPC to freight shipment time was a convenient, objective, and thorough method of analyzing car movement data and getting answers to concerns regarding both the speed and consistency of rail transportation. 
In the broadest sense, providers of public transit service have a general obligation to the public to offer service that is safe, reliable, and cost-effective. This desire has lead to the development and implementation of various quality tools and programs to fulfill this need. For example, in the United Kingdom, the company formed to revitalize Britain's railways, Network Rail, implemented Six Sigma for its West Coast Route Modernization Project. The company is using Six Sigma as a quality improvement tool to investigate and quantify causes of delay and establish remedial action. In addition to cost savings, the company is able to offer more predictable performance with less variation (Connolly 2003; Network Rail 2003).

In Hong Kong, the Kowloon Canton Railway Corporation's (KCRC) infrastructure and building department has undergone efforts to focus on the satisfaction of its internal customers as part of efforts in continuing quality enhancement and as a systematic way to boost quality awareness within the KCRC (Tam and Hui 1996). Transit ride quality and passenger levels are also becoming a common measure of rider satisfaction studied by transit agencies in the United States. The Transit Capacity and Quality of Service Manual (Transit Cooperative Research Program 2003) provides details on how to capture this information based on the transit user's perspective, but, again, does not provide statistically valid ways to measure and analyze vehicle data.

Some of the larger transit agencies in the United States also have undergone quality training programs for their engineering and construction departments. For example, the Houston Metropolitan Transit Authority underwent training on Federal Transit Administration (FTA) QA/QC requirements for design and construction, which included familiarization with ISO 9000 and review of their quality program (Burridge-Kowalik 2003).

Statistically valid models to measure, monitor, and control vehicle on-time performance also have been developed. These include Total On-Time Operation (TOTO) and Schedule Constraint and Route Analysis Model (SCRAM) by Oregon State University's Transportation Research Institute and the Department of Industrial and Manufacturing Engineering (Safford 1990). These and other similar tools are being developed and used by transit agencies to monitor their operations, but there are few formalized, statistically-valid systems used to assess the maintenance of transit vehicles, particularly those for bus fleets. 


\section{SEPTA's Quality Initiative}

SEPTA is responsible for providing and maintaining transit service to the greater Philadelphia area in the form of trolleys, subways, commuter rail, and buses. In addition to the increasing pressure to do more with less, SEPTA, like all other subsidized transit agencies in the United States, must adhere to Federal guidelines in providing its service, including following a strict vehicle maintenance schedule. This helps to ensure that the vehicles will achieve their full useful lives and ultimately demonstrate to taxpayers that funding is being used prudently.

The aging infrastructure of SEPTA's service area, combined with the reductions in funding, created a challenging situation for SEPTA, which essentially needed to find ways to address budget cuts. The authority partially responded to this need through creation of the Quality Assurance Department. The responsibility of this group was to assist with programs and practices that would help improve the efficiency and effectiveness of the agency.

SEPTA's Quality Assurance Department provided appropriate training (Chaudhry and Higbie 1989; Patterson 2003) to many groups within the organization. A course in SPC was developed to train employees who performed vehicle maintenance, and the Statistical Process Control Reference Handbook was produced for use by employees (Patterson 2003). All of the Bus Operations Division received training in SPC, including the Maintenance and Transportation Groups. SEPTA's Safety and Risk Management Group also was given SPC training. The Quality Assurance Department customized the training to meet the needs of each department using its specific data. In terms of the presentation techniques for this information, the same types of techniques, control charts, histograms, and composite diagrams were developed for every group, all grounded in the same SPC philosophy for SEPTA. Additional training was developed to be used as a follow-up to improve processes and detail how to take corrective actions. The intended use of SPC was to serve as a measuring device to help demonstrate opportunities for improvement in existing processes. Actions were to be taken by the specific departments based on these results.

\section{SPC at SEPTA}

SPC has been formally defined as a methodology for monitoring a process to identify special causes of variation that signals the need to take corrective action when it is appropriate (Evans and Lindsay 2005). In practical terms, SPC is a statistical 
procedure that uses control charts to determine if any part of a production process is not functioning properly and could cause poor quality (Russell and Taylor 2003). SPC is a relatively recent undertaking by transportation organizations to look at their production processes to see if there is variance from typical performance and ultimately prevent poor quality before it occurs (Anonymous 1998; Benneyan and Chute 1993).

SEPTA realized the importance of SPC training as part of its overall quality program and embarked on a comprehensive training plan for several departments concerned with bus maintenance. A major component of this effort at SEPTA was the use of SPC to track problems in the bus fleet. Although the training was implemented over a period of about three years, it was perceived as a complicated process for many of those receiving the training.

At the time, SEPTA called in buses from service to undergo a two-part maintenance procedure. The first part was called the In-Process Inspection. This inspection was performed in the Rering and Teardown shops. The Rering Shop examined the engine, transmission, heating/ventilation/air conditioning system, and the electrical system. The Teardown Shop looked at the undercarriage and the chassis.

The second part of SEPTA's vehicle inspection was the Final Inspection. The Final Inspection took place in the Body and Paint shops. Areas examined in the Body Shop included the following components of the bus: interior, passenger doors, electrical system (including lights), body and access doors, glazing, windshield wipers, washer and accessories. The Paint Shop inspection entailed examining the bus for defects in the paint and finish and determining areas requiring touch-ups.

Prior to SPC implementation, SEPTA routinely performed inspections of its buses based on required maintenance schedules and completed appropriate repairs, but made no attempt to analyze the data collected as part of its typical maintenance practice. With the implementation of SPC, SEPTA had the ability to determine whether the number of problems or "defects" was under control and within the desired limits. Defects were classified as problems found during the inspection process with particular components that would compromise the operability, safety, or comfort of the vehicle. If the number of defects was determined to be out of control, further investigations were then performed to determine the nature or cause of the increased defects. Then, depending on what the investigations revealed, the appropriate steps were taken to bring the number of defects back under control. 
The data gathered from the two inspection stages were presented graphically. These graphs included pie, bar, and control charts. The pie and bar charts were principally for presentation purposes to visually represent the results of the inspections. For example, a pie chart depicting the percentage of defects by component is shown in Figure 1, and a bar chart displaying discrepancies by component, by month is shown in Figure 2.

The SPC training at SEPTA included instruction on several different types of control charts that would be applicable in the various processes for bus fleet maintenance. In some situations, SEPTA's Operations Support Quality Assurance Department was not only interested in whether the vehicle was defective, but also in the number of defects it had. These defects could be attributable to factors such as route miles, route characteristics, or number of passengers served. C-charts are commonly used to control the total number of defects per unit when the subgroup size is constant (Evans and Lindsay 2005). Therefore, C-charts were the most appropriate type of control chart in SEPTA's analysis of the number of defects per unit in the two-part maintenance procedure.

\section{Figure 1. Percentage of Defect by Component, Berridge Shop}

\section{Berridge Shop VOH \\ Final February 19XX Body Shop Inspection Total Number of Defects: 189}

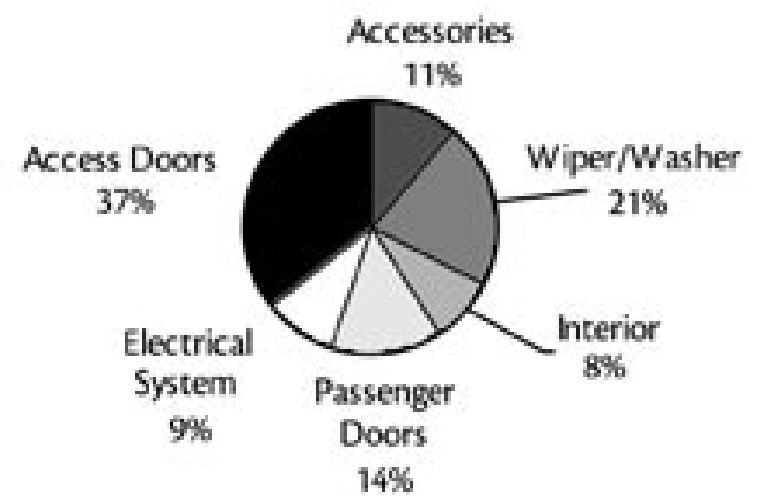




\section{Figure 2. Discrepancies by Component, by Month, Berridge Shop}

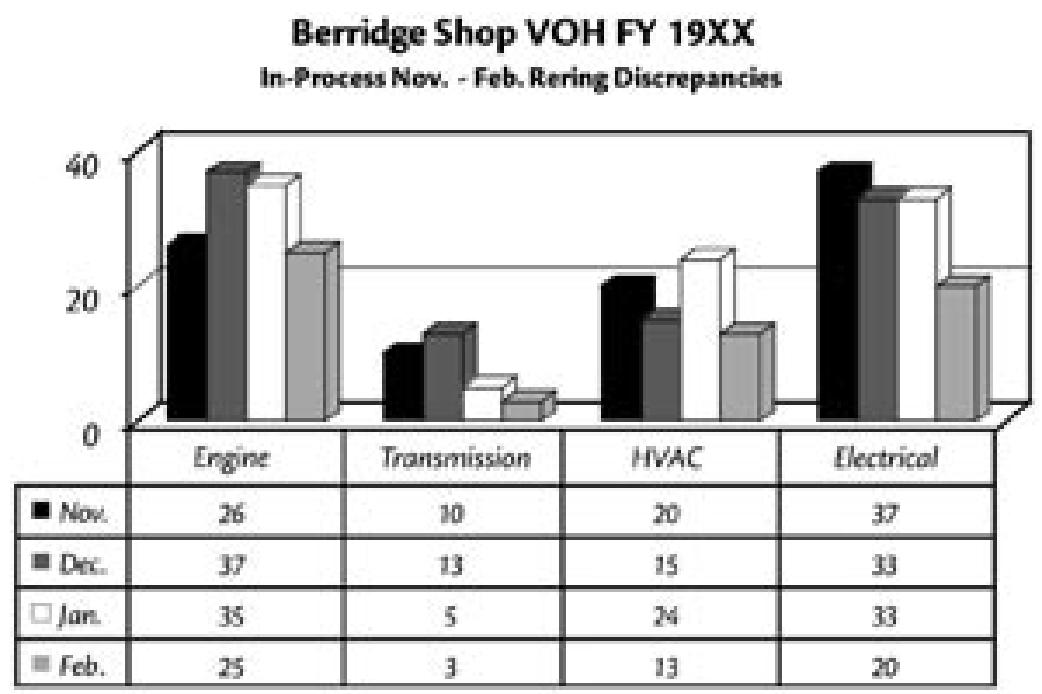

In this article, we describe the inspection of vehicles over a four-month period as part of required maintenance schedules. Inspectors were given preprinted inspection sheets to facilitate the process in determining what represented a problem or "defect." Depending on the specific item being inspected, the defective item would either be replaced or repaired. The inspection sheet broad categories are shown in Table 1. These sheets clearly defined what items were to be inspected and reported on as far as performance or quality. An example of a specific item is shown in Table 2. 
Table 1. In-Process and Final Inspection Components Checklist

\section{Southeastern Pennsylvania Transportation Authority Operations Support}

\section{IN PROCESS INSPECTION CHECK OFF}

A. Teardown Inspection Check Off
A1. Front Suspension

A2. Rear Suspension

A3. Air \& Fuel

A4. Break Reline

A5. Steering

A6. Axles

A7. Structural

B. \& C. Rering Inspection Check Off
B1. Engine Line
B2. Climate Control
B3. Electrical
B4. Cooling System
B5. Engine Spine
B6. Air Intake \& Exhaust
B7. Road Test \& Functional Test
C2. Wheelchair Lift

\section{FINAL INSPECTION SHEETS}

C. Body Shop Inspection Check Off

C1. Interior

C2. Exterior

D. Paint Inspection Check Off

D1. Body \& Paint

-Functional Checks

-Interior Checks

-Exterior Checks

D2. Paint - Check Off Sheets

-Exterior Checks

-Interior Checks 


\section{Table 2. Front Suspension Checklist}

A1 FRONT SUSPENSION

A1.1 CHECK NEW SHOCK ABSORBERS

CHECK REPL. REPAIRED

A1.2 CHECK NEW BELLOWS AND PISTONS

A1.3 CHECK NEW CONTROL ARM BUSHINGS CHECK NEW UPPER CONTROL ARMS

A1.4 CHECK FOR NEW HOLLOW SPRINGS

These sheets were collected after each inspection, and the number of defects per bus by shop was totaled. These data were then used in conjunction with Statistical Process Control software (Shewhart 1993) to generate the C-charts. Table 3 shows a sampling of the application at different stages of the two-part maintenance procedure.

Table 3. C-Chart Calculations

\section{Calculation of the Standard Deviations of the Distributions Per Shop}

$\begin{array}{llll}a & b & c & (a-b) / c\end{array}$

Mean of No. of Std. Std. Deviation

Distribution Deviations of Distribution

$\begin{array}{lccccc}\text { Shop } & \underline{\mathrm{LCL}} & \underline{\mathrm{UCL}} & \underline{\bar{C}} & \underline{\mathrm{Z}} & \underline{\sqrt{\mathrm{C}}} \\ \text { Teardown } & 0.00000 & 7.76153 & 2.76923 & 3 & 1.66410 \\ \text { Rering } & 2.43182 & 24.41433 & 13.42308 & 3 & 3.66375 \\ \text { Body } & 5.58349 & 31.37651 & 18.48000 & 3 & 4.29884 \\ \text { Paint } & 0.08035 & 18.23965 & 9.16000 & 3 & 3.02655\end{array}$

Note: $\quad \mathrm{LCL}=$ Lower Control Limit

$\mathrm{UCL}=$ Upper Control Limit

$\overline{\mathrm{C}}=$ Mean of Distribution 
From this summary table, we chose the Paint Shop to illustrate SEPTA's experience with SPC. Figure 3 represents an application of C-chart with Upper Control Limit $(\mathrm{UCL})$ and Lower Control Limit $(\mathrm{LCL})$ set at three standard deviations from the mean of the process in the Paint Shop. The C-chart is theoretically rooted in Poisson distribution. Since, on a bus, there could potentially be a very large number of defective places, the proportion of defects relative to the inspection area is usually small. Hence, in applying the Poisson distribution to C-charts, an inspection unit may be of any kind. In the example presented here, SEPTA used the sampling unit of one bus (Duncan 1986).

It can be observed from the control chart that all points are within the control limits and, in fact, they are within two standard deviations of the mean. However, based on the fact that there are seven points below the center line during the month of December, this could be construed as a cause of concern. However, it is good cause of concern since there are less nonconformities per unit. From a control chart perspective, since it is a preventive tool, management still needs to investigate the situation observed and learn from it. In addition, these points

\section{Figure 3. C-Chart Application from SEPTA's Paint Shop}

\section{BERRIDGE SHOP VOH - FINAL INSPECTION DEFECTS PER BUS}

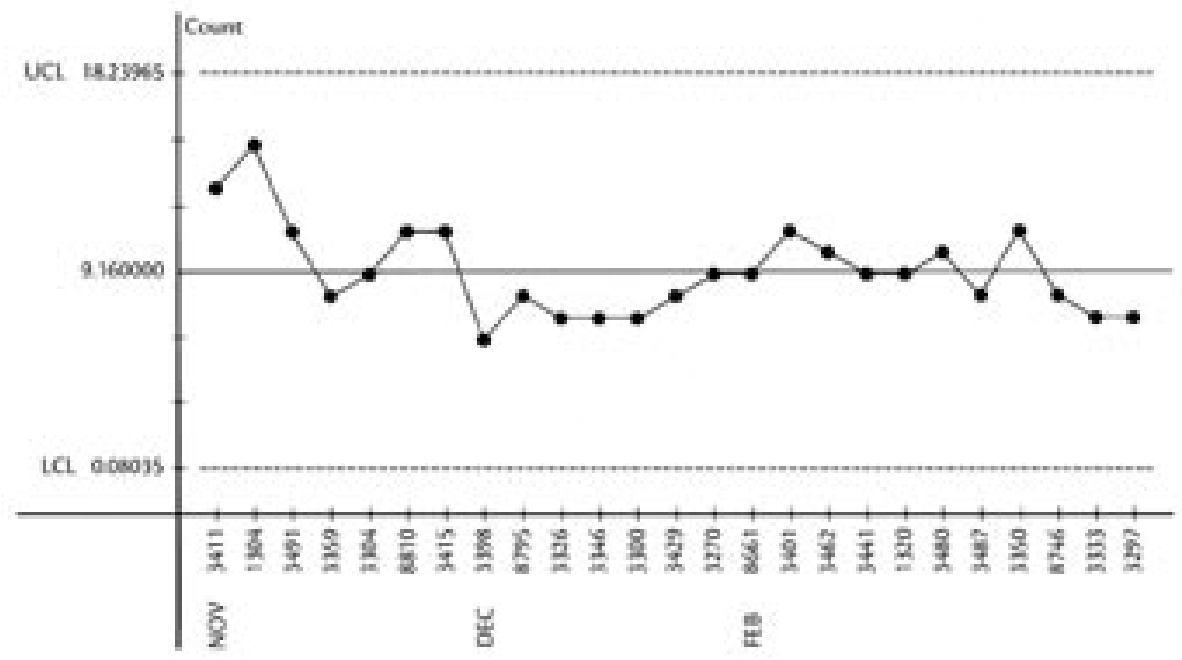

PAINT $\times$ NO INSP, FOR JAN. 
are within one standard deviation below the mean of the process and hence one could argue that the process is settling down. Therefore, the nature or cause of this trend could be investigated to exploit it. Furthermore, if there is a shift in the process mean, management can then decide to recalculate the mean of the process by eliminating points before the shift. Such exploitation also could reduce the mean number of defects in the Paint Shop, which, in turn, would change the $\mathrm{UCL}$ and $\mathrm{LCL}$.

\section{Benefit of SPC to SEPTA}

In this article we illustrated that SEPTA was able to introduce and implement SPC as part of its quality improvement efforts. From this example, we learn that the use of quality control tools can be employed for fleet inspections in a public transit agency environment. The implementation of such tools, however, requires a substantial effort in terms of developing procedures, training, and other continual means of making the program understandable, real, and useful.

In terms of overall benefits experienced by SEPTA in its use of SPC, the authority first and foremost became aware of the benefit of examining trends versus month-by-month comparisons. SEPTA realized the impact of its decisions and understood that implementing corrective actions would have an effect on subsequent processes and results. After attending the training course, many of the staff truly appreciated the philosophy that there is always room for improvement and became interested in analyzing the data produced from SPC.

With the creation of a Quality Assurance Department, SEPTA's top management demonstrated its commitment in improving the effectiveness of the operations in the organization. Their use of process control procedures assisted in gathering timely information on whether the vehicles in service were meeting service requirements and enabled them to detect shifts in the quality of service that could potentially be attributable to problems that would be encountered by a portion of the bus fleet at some point in the future. For example, if a problem was found with the rear suspension on a number of the vehicles inspected, and a fleet defect was identified, SEPTA would take proactive action to repair the entire fleet. The actual control phase occurred when a corrective action was taken (e.g., repair, contracting with a new supplier, routine maintenance, etc.).

The use of SPC within SEPTA involved a tremendous education process, and it was hoped that the maintenance and quality assurance supervisors would be able to 
put more control in the hands of the employees on the shop floor. As an example, if a recurring problem was noted with electrical systems on vehicles, by using SPC, SEPTA would be able to determine the source of the problem, such as a bad lot of bulbs, and take steps to correct the problem. SEPTA's goal was to have its maintenance personnel become proactive and think analytically, focusing attention on the source of a problem, not just an immediate solution to a specific defect.

SEPTA used SPC over several years and was optimistic how the use of SPC would provide increased benefit to the organization in terms of cost savings and quality of service. SEPTA's expectations regarding bus defects was that the use of SPC would accomplish change and impart responsibility on the persons who are involved in the "hands-on" maintenance of the vehicles. With its day-to-day use, SEPTA was able to track problem trends, identify problems with particular bus fleets, and work to obtain compensation or replacement for defective parts or items under warranty.

In the overall picture for using SPC to document defects, SEPTA hoped to influence management, reduce claims, and increase safety. SEPTA's Surface Division in charge of these vehicles hoped the use of SPC would increase the mean distance between vehicle failures as well as increase the unit reliability of the maintenance shops. It was also anticipated that defect trends would be easily documented and monitored, which would ultimately lead to reduction in costs and maintenance budgets. During the period of study, SEPTA's Quality Assurance Department was successful in obtaining additional compensation from warranty claims and achieved the resulting cost savings from this initiative. Due to a variety of reasons, the actual cost savings were not made available as part of this study.

While, in the end, the mindset of managers at SEPTA ultimately changed to use trend analyses to implement improvements in a process versus a month-tomonth comparison of numbers, there is applicability for future use of SPC in a public transit environment.

This study demonstrates that the use of control charts in the transit industry as an active, real-time tool is viable and has the potential to be replicated in other transit agencies to control costs and monitor problem areas. 


\section{References}

Anonymous. 1998. Winterizing by the numbers. Fleet Equipment 24, 12: 32-34.

Benneyan, J. C., and A. D. Chute. 1993. SPC, process improvement, and the Deming PDCA circle in freight administration. Production and Inventory Management Journal 34, 1: 35-40.

Bowman, J. S., and R. Hellien. 1998. Total quality management in Florida: Implementation in state agencies. Public Administration Quarterly 22, 1: 114-129.

Burridge-Kowalik, L., Director of Operations Maintenance Support, Metropolitan Transit Authority of Harris County Texas. July 7, 2003. Personal telephone conversation.

Chaudhry, S. S., and J. R. Higbie. 1989. Practical implementation of Statistical Process Control in a chemicals industry. International Journal of Quality and Reliability Management 6, 5: 37-48.

Connolly, E., West Coast North Area Planning Manager, Network Rail, UK. July 15, 2003. Personal email correspondence.

Duncan, A. J. 1986. Quality control and Industrial statistics. 5th ed. Homewood, IL: Richard D. Irwin, Inc.

Evans, J. R., and W. M. Lindsay. 2005. The management and control of quality. 6th ed. Cincinnati, OH: South-Western/Thomson Learning.

Obeng, K., and I. Ugboro, 1996. Applications of TQM in public transit firms. Transportation Quarterly 50, 3: 79-94.

Network Rail. June 2003. Interim Review: Business Plan Update. Available at http:// www.railtrack.co.uk/documents/interim_review.pdf.

Patterson, C., Transportation Systems Specialist, Southeastern Pennsylvania Transportation Authority. June 4, 2003. Personal telephone conversation.

Pohlot, B. R., Senior Engineering Manager, PB Transit \& Rail Systems. June 26, 2003. Personal telephone conversation.

Richards, C. E. 1984. Monitoring rail transit time using statistical process control. The Logistics and Transportation Review 20, 4: 509-516.

Russell, R. S., and B. W. Taylor III. 2003. Operations management, 4th ed. Upper Saddle River, NJ: Prentice Hall/Pearson Education, Inc. 
Safford, R. R. 1990. 'Toto: Total On-Time Operations' A microcomputer-based statistical quality control procedure for measuring, monitoring, analyzing, and controlling transit system on-time performance. Computers and Industrial Engineering 19, 1-4: 276-279.

Schwager, D. S., and L. C. MacDormand. 1992. Total quality management: Experience of four transit systems. Transportation Research News 163 (NovemberDecember): $3-7$.

Shewhart, M. 1993. SPCEXpert. Version 2.1S, Kettering, OH: Quality Software Designs, Inc.

Southeastern Pennsylvania Transportation Authority. 1994. Statistical process control reference handbook. Southeastern Pennsylvania Transportation Authority.

Takyi, I. K., K. Obeng, and I. Ugboro. 1993. Total Quality Management for public transit systems. Transportation Quarterly 47, 2: 167-183.

Tam, C.M., and Moses Y. T. Hui. 1996. Total quality management in a public transport organization in Hong Kong. International Journal of Project Management 14, 5: 311-315.

Transit Cooperative Research Program. 2003. Transit capacity and quality of service manual, 2nd ed., TCRP Report 100.

\section{About the Authors}

ANNA LYNN SMITH (smitha@pbworld.com) is a senior transportation planner with Parsons Brinckerhoff in Philadelphia. She received a B.S. in civil and architectural engineering from Drexel University and an M.B.A. from Villanova University with a concentration in operations management and marketing. Her career experience includes transit system financial analyses, quality system development and implementation, rail engineering, planning, and operations.

Sohall S. ChaUdhry (sohail.chaudhry@villanova.edu) received a Ph.D. from Columbia University in industrial engineering and operations research. He is a professor of operations management and management science in the Department of Decision and Information Technologies at Villanova University. His research interests include supply chain management and management and control of quality. He has published numerous papers in journals such as Decision Sciences, European Journal 
of Operational Research, Expert Systems, Journal of the Operational Research Society, Journal of Quality and Reliability Management, Management Science, and Systems Research and Behavioral Science. 